\title{
Who responds? An examination of response rates to a national postal survey of Aboriginal and Torres Strait Islander adults, 2018-2019
}

Alyson Wright ${ }^{1 *}$, Katherine Ann Thurber ${ }^{1}$, Mandy Yap ${ }^{2}$, Wei Du' ${ }^{1}$ Emily Banks ${ }^{1}$, Jennie Walker ${ }^{1}$, Faye Irwin' Will Sanders ${ }^{2}$ and Raymond Lovett $^{1}$

\begin{abstract}
Background: Evidence on the effectiveness of postal recruitment methods for Indigenous peoples is lacking. Mayi Kuwayu, the National Study of Aboriginal and Torres Strait Islander Wellbeing, uses multi-staged sampling. We aimed to test postal surveys as a primary recruitment method, analysing preliminary response rate data to inform the Study's ongoing sampling approach.

Methods: Twenty thousand adults aged $\geq 16$ years were sampled from Aboriginal and Torres Strait Islander people enrolled in the Medicare Australia Enrolment Database. We calculated response rates at 4 and 15 weeks, overall and by age group, gender, state/territory and remoteness.

Results: The overall response rate was 2.3\% ( $n=456 / 20000)$. Highest response rates were observed among males and females $\geq 50$ years from major cities $(6.0,95 \% \mathrm{Cl} 4.4-7.9$ and 5.5\%, 4.1-7.2, respectively) and regional areas (6.0\%, 4.6-7.6 and $6.2 \%, 4.9-7.7$, respectively). Younger age groups and remote areas had lower response rates; all remote age groups $<50$ years had a response rate $\leq 0.6 \%$. While most participants responded on the paper surveys, online responses were more common among younger age groups and, respondents with higher education levels and whose first language was not English.

Conclusion: Using a postal survey, we observed response rates of $\geq 5.5 \%$ among older Aboriginal and Torres Strait Islander adults in major cities and regional areas; response rates were lower in other groups. A two-stage postal distribution approach provided an opportunity to adapt sampling approaches to different demographic groups. Based on initial response rates, the sampling strategy was revised to send postal surveys to groups with higher response rates groups and focus field recruitment strategies on low response groups.
\end{abstract}

Keywords: Indigenous, cohort, recruitment, postal surveys, response rates, Aboriginal, Torres Strait Islander

\section{Background}

It is internationally recognised that improvements in data systems are needed to support action and progress in Indigenous peoples' health outcomes $[1,2]$. This includes the

\footnotetext{
* Correspondence: alyson.wright@anu.edu.au

National Centre for Epidemiology and Population Health, Research School of Population Health, Australian National University, Canberra, Australia

Full list of author information is available at the end of the article
}

need for longitudinal data on wellbeing measures that are defined by Indigenous people. These calls also recognise the importance of Indigenous peoples' role in determining data processes, including the sampling approaches applied. Longitudinal (cohort) studies can and do contribute to the growing evidence base on Indigenous perspectives on health and wellbeing but to date Indigenous cohort

(๑) The Author(s). 2020 Open Access This article is licensed under a Creative Commons Attribution 4.0 International License, which permits use sharing, adaptation, distribution and reproduction in any medium or format, as long as you give

appropriate credit to the original author(s) and the source, provide a link to the Creative Commons licence, and indicate if changes were made. The images or other third party material in this article are included in the article's Creative Commons licence, unless indicated otherwise in a credit line to the material. If material is not included in the article's Creative Commons licence and your intended use is not permitted by statutory regulation or exceeds the permitted use, you will need to obtain permission directly from the copyright holder. To view a copy of this licence, visit http://creativecommons.org/licenses/by/4.0/. The Creative Commons Public Domain Dedication waiver (http//creativecommons.org/publicdomain/zero/1.0/) applies to the data made available in this article, unless otherwise stated in a credit line to the data. 
studies in health have been small in scale or confined to geographic areas or language groups.

Postal surveys have been routinely used as a primary method of recruitment for large-scale national cohort studies and are a particularly efficient method for dispersed populations [3]. Yet, postal response rates are unknown for most Indigenous populations, because cohort studies in these populations have tended to opt for other recruitment approaches [4-6]. Examination of response rates is needed to determine if postal surveys are an effective mechanism for the collection of large scale, longitudinal data on Indigenous health.

In Australia, established Indigenous cohort studies (including: Aboriginal Birth Cohort Study [7], Longitudinal Study of Indigenous Children [8], Study of Environment on Aboriginal Resilience and Child Health [9], Talking about the Smokes [10], Antecedents of Renal Disease in Aboriginal Children, Next Generation Youth Wellbeing Study [11]) have used field recruitment to sample from known populations in particular urban, regional, and remote areas. These field-based sampling approaches use purposive or strata-sampling with local Aboriginal or Torres Strait Islander data collectors who are employed or supported by partner Indigenous services. The faceto-face approach facilitates multiple options for completion of a survey, including self-completion; completion through interview; and, use of interpreters.

Aboriginal and Torres Strait Islander people comprise $3 \%$ of the Australian population, with a substantial proportion (19\%) living in remote areas compared with $2 \%$ of non-Indigenous Australians living remotely [12]. These factors increase the complexities and resources required to recruit a national, heterogeneous sample that reflects the cultural, linguistic and geographic diversity of the population. All the cited Indigenous cohort studies are small-scale $(n<3000)$ and most have focussed on linguistically or culturally specific communities or geographic regions, presenting a substantial gap in largescale, national longitudinal approaches to data collection among Aboriginal and Torres Strait Islander Australians.

Australian cohort studies have demonstrated that Aboriginal and Torres Strait Islander people do respond to postal surveys, though not always to the same extent as the total Australian population. The 45 and Up Study, involving adults aged $\geq 45$ years from New South Wales (NSW), recruited 1939 Aboriginal participants through postal surveys $(0.7 \%$ of overall cohort population compared to $2.8 \%$ of the NSW population). The 45 and Up survey sampled from the Medicare Australia database, which provides close to complete coverage of the total Australian population [13]. The 1999 Australian Women's Health Survey (AWHS) found the proportion of Aboriginal and Torres Strait Islander women recruited from the postal survey was similar to the total
Indigenous population $(2.5 \%, n=900)$ [14]. However, Aboriginal women living remotely were underrepresented in the AWHS cohort, despite an oversampling of remote areas [15]. These respective studies achieved an overall response rates between 18 and 44\% in total sample population, but response rates specific to Indigenous participants were not calculated $[15,16]$. In both studies, the Indigenous status of participants could only be identified post recruitment.

Until recently, it has been virtually impossible to determine a sampling frame to specifically distribute postal surveys to Aboriginal and Torres Strait Islander people. Telephone books and electoral rolls do not include Indigenous status information. Hospital records and other health registers do record Indigenous status, however data can: be unreliable due to poor recording of Indigenous status; be restricted due to privacy; be available only at state or territory-levels [17]; and include only the unwell population or birth population [18-20]. In 2006, Medicare added an Indigenous status question on enrolment and renewal forms [21]. This change has enabled researchers to request sampling of Indigenous persons from the Medicare Australia Enrolment Database. At October 2017, 533,832 people in the Medicare Australia Enrolment Database had indicated they were Aboriginal and/or Torres Strait Islander, covering $\sim 60-70 \%$ of the total Indigenous population.

To our knowledge, Mayi Kuwayu, the National Study of Aboriginal and Torres Strait Islander Wellbeing is the first to test postal recruitment for an Indigenous cohort. The Study is a cohort of Aboriginal and Torres Strait Islander adults ( $\geq 16$ years), designed to enable quantification of the relationships between health, culture and wellbeing [6]. The baseline sample is being recruited through a two-stage postal distribution: a preliminary distribution of 20,000 surveys and a main distribution of 180,000 surveys (total $N=200,000$ ). The sample is supplemented with field recruitment. The aim of this crosssectional analysis was to determine response rates to the preliminary postal distribution, overall and by age group, gender, level of remoteness and by jurisdiction, to inform the Study's ongoing recruitment approaches.

\section{Methods}

\section{Mayi Kuwayu study preliminary sample frame}

Eligibility for receiving a Mayi Kuwayu survey in the post was defined by the following criteria: recorded as Aboriginal and/or Torres Strait Islander in the Medicare Enrolment Australia Database; and, aged 16 years or older. We used total Indigenous identified adults $(\geq 16$ years) in the Medicare Australia Enrolment Database to determine a stratified sample $(n=20,000)$ according to age, gender and remoteness (Table 1 ). 
Table 1 Sampling frame for the Mayi Kuwayu Study preliminary postal distribution ( $n=20,000), 30$ October 2018

\begin{tabular}{|c|c|c|c|c|c|}
\hline & & Major cities & Regional & Remote & Total \\
\hline \multicolumn{6}{|l|}{ Females } \\
\hline \multirow[t]{3}{*}{$16-24$} & Total Indigenous persons enrolled in Medicare ${ }^{a}$ & 15,600 & 21,300 & 9300 & 46,200 \\
\hline & $\%$ enrolled & $4.6 \%$ & $6.3 \%$ & $2.8 \%$ & $14.0 \%$ \\
\hline & Number sent the postal survey & 928 & 1267 & 553 & 2748 \\
\hline \multirow[t]{3}{*}{$25-34$} & Total Indigenous persons enrolled in Medicare ${ }^{a}$ & 16,200 & 19,300 & 9800 & 45,300 \\
\hline & $\%$ enrolled & $4.8 \%$ & $5.7 \%$ & $2.9 \%$ & $13.5 \%$ \\
\hline & Number sent the postal survey & 964 & 1148 & 583 & 2695 \\
\hline \multirow[t]{3}{*}{$35-49$} & Total Indigenous persons enrolled in Medicare ${ }^{a}$ & 13,500 & 16,900 & 10,300 & 40,700 \\
\hline & $\%$ enrolled & $4.0 \%$ & $5.0 \%$ & $3.1 \%$ & $12.1 \%$ \\
\hline & Number sent the postal survey & 803 & 1005 & 613 & 2421 \\
\hline \multirow[t]{3}{*}{$\geq 50$} & Total Indigenous persons enrolled in Medicare ${ }^{a}$ & 14,900 & 19,300 & 10,000 & 44,200 \\
\hline & $\%$ enrolled & $4.4 \%$ & $5.7 \%$ & $3.0 \%$ & $13.1 \%$ \\
\hline & Number sent the postal survey & 886 & 1148 & 595 & 2629 \\
\hline \multicolumn{6}{|l|}{ Males } \\
\hline \multirow[t]{3}{*}{$16-24$} & Total Indigenous persons enrolled in Medicare ${ }^{a}$ & 13,800 & 19,800 & 8800 & 42,400 \\
\hline & $\%$ enrolled & $4.1 \%$ & $5.9 \%$ & $2.6 \%$ & $12.6 \%$ \\
\hline & Number sent the postal survey & 821 & 1178 & 523 & 2522 \\
\hline \multirow[t]{3}{*}{$25-34$} & Total Indigenous persons enrolled in Medicare & 14,400 & 18,500 & 8600 & 41,500 \\
\hline & $\%$ enrolled & $4.3 \%$ & $5.5 \%$ & $2.6 \%$ & $12.3 \%$ \\
\hline & Number sent the postal survey & 857 & 1101 & 512 & 2470 \\
\hline \multirow[t]{3}{*}{$35-49$} & Total Indigenous persons enrolled in Medicare ${ }^{a}$ & 11,900 & 15,900 & 9100 & 36,900 \\
\hline & $\%$ enrolled & $3.5 \%$ & $4.7 \%$ & $2.7 \%$ & $11.0 \%$ \\
\hline & Number sent the postal survey & 708 & 946 & 541 & 2195 \\
\hline \multirow[t]{3}{*}{$\geq 50$} & Total Indigenous persons enrolled in Medicare & 12,700 & 17,100 & 9200 & 39,000 \\
\hline & $\%$ enrolled & $4.0 \%$ & $5.0 \%$ & $3.0 \%$ & $12.0 \%$ \\
\hline & Number sent the postal survey & 756 & 1017 & 547 & 2320 \\
\hline \multirow[t]{3}{*}{ Total } & Total Indigenous persons enrolled in Medicare ${ }^{a}$ & 113,000 & 148,100 & 75,100 & 336,200 \\
\hline & $\%$ enrolled & $33.6 \%$ & $44.1 \%$ & $22.3 \%$ & $100.0 \%$ \\
\hline & Number sent the postal survey & 6723 & 8810 & 4467 & 20,000 \\
\hline
\end{tabular}

${ }^{\mathrm{a}}$ Total Indigenous persons (rounded to the hundred) in Medicare Australia Enrolment Database, data provided by Department of Health on 19 June 2018

The Department of Human Services (DHS) mailed surveys to individuals, randomly selected from the total pool of eligible persons in each age-sex-remoteness stratum. The survey pack included: a prepaid return envelope; an eightpage coloured survey; and, an information sheet. DHS required use of a standard government cover letter and outer envelope. The letter informed recipients that DHS was sending the information on behalf of the research team. No addresses or names were provided to the research team. In addition to the paper survey, respondents were provided options to complete the survey online or via a free-call helpline. The survey packs were mailed on 30 October 2018.

\section{Survey respondent eligibility}

An eligible survey respondent for inclusion in this analysis was defined by: (i) aged 16 years or older; and, (ii) responded to the Mayi Kuwayu postal survey in the preliminary phase (30 October 2018-11 February 2019). Paper surveys with IDs between 100,000 and 200,000 were included, as this was within the range allocated for postal distribution. Online survey responses were included if respondents selected "sent to me in the post" or "sent to someone I know" when answering the survey question, "How did you find out about the survey?" All surveys completed in field-based recruitment were excluded.

\section{Variables}

We calculated age from reported date of birth and date of survey completion, and recoded to age groups 16-24, $25-34,35-49$ and $\geq 50$ years. If the date of survey completion was missing, the age was calculated at 11 
February 2019 (the cut-off point for the preliminary phase). Gender was a self-reported survey item and classified as female, male or other. Reported postcode of residence was used to define the Remoteness Areas based on Australian Geographical Standard Classification (AGSC), which categorises areas as 'major cities', 'inner regional', 'outer regional', 'remote' or 'very remote' [22]. Remoteness Areas were grouped: major cities, regional (inner and outer regional), remote (remote and very remote). For postcodes mapped on to multiple Remoteness Areas, we assigned the Remoteness Area with the highest proportion of population, as determined by ABS [23].

We used other survey variables (education, financial status and first language) to characterise respondents. Education level was derived from the highest level of completed education and included the categories: no schooling, up to Year 10, Year 12, technical/trade and university qualification. Household financial status was defined from the question "What words describe your family's money situation"? Responses include: 1"We have a lot of savings", 2 "We have some savings", 3 "We have just enough to get us to the next payday", 4"We run out of money before payday", 5"We are spending more than we get", 6"Unsure". These were grouped as "Savings" [1, 2], "Just enough" [3], "No savings" [4, 5], Unsure [6]. First language was defined as: "Aboriginal or Torres Strait Islander language", "English" or "other". We generated a new variable to represent mode of completion (online versus paper survey) based on data from the survey provider.

\section{Statistical analysis}

The response rate was defined as the number of returned postal surveys divided by the total number of surveys sent, according to the sample frame (Table 1), overall and within each stratum (age, gender, remoteness). We analysed response rates to the postal distribution at two time points (4 weeks and 15 weeks). We separately calculated response rates based on jurisdiction (state or territory). We report $95 \%$ confidence intervals for response rates assuming a binomial distribution. We summarised the number of responses over time (by week) and by response mode (paper survey, online).

The respondents were characterised according to age, gender, remoteness, education level, financial status and first language, and we report numbers and percentages. All missing or unclassifiable data were reported and listed as 'unclassifiable'. We compared response mode (online versus paper) across sociodemographic characteristics of respondents using Fisher's exact test. We used the stratalevel response-rate results at 4 weeks to inform the mainstage postal sample for the Mayi Kuwayu Study $(N=180$, 000). We compared results at 4 weeks to 15 weeks to assess if response rates were sensitive to time. Analysis was undertaken in STATA version 15.
To gain insight into the extent of surveys that did not reach the intended respondent, we reviewed data on return to senders provided by the DHS. In addition, we reviewed reasons for non-completion of the postal survey from Mayi Kuwayu Study helpline callers and, field researcher reports on reasons why people who received the postal survey did not respond.

\section{Approval and ethics}

Ethics approvals were granted for the conduct of the Study from national and state/territory Human Research Ethics Committees. Internal governmental approvals (Department of Health and DHS) were obtained to post surveys specifically to Aboriginal and Torres Strait Islander people enrolled in Medicare.

\section{Results}

Response rates to Mayi Kuwayu preliminary phase postal distribution

A total of 465 individuals responded to the preliminary Mayi Kuwayu postal distribution. One participant was under the age of 16 years, seven participants were nonIndigenous and one participant completed the survey twice, the duplicate response and non-eligible participants were excluded from the analysis $(465-9=456)$. The overall response rate was $2.3 \%(\mathrm{n} / N=456 / 20000)$. Response rates were highest in major cities $(2.9,95 \% \mathrm{CI}$ : $2.5-3.3)$ and substantially lower in remote areas $(0.8 \%$, 0.6-1.1). There were similar response rates between men and women (male 2.1\%, 1.8-2.4, versus female $2.4 \%, 2.1-2.7)$. Older age groups were more likely to respond than younger age groups (Table 2).

The highest response rates were obtained in strata levels aged $\geq 50$ years: males from regional areas $6.0 \%$ (4.6-7.6), males from major cities $6.0 \%$ (4.4-7.9), females from major cities $5.5 \%$ (4.1-7.2), and females from regional areas $6.2 \%$ (4.9-7.7) (Table 2). Response rates were $\geq 2.5 \%$ in these jurisdictions: Australian Capital Territory (6.3\%, 3.1-11.3), New South Wales (3.3\%,2.8-3.8), Tasmania (5.0\%,3.4-7.1), Victoria $(3.6 \%, 2.7-4.7)$ and $<2 \%$ in Queensland (1.7\%,1.4-2.9), Western Australia (1.2\%,0.81.6), Northern Territory (0.6, 0.3-1.1) (Table 3).

\section{Responses over time and by response mode}

Most surveys were received by the end of the fourth week ( $n=390,85.5 \%)$. Sixty-six (14.5\%) postal surveys were received between four and 15 weeks (Table 4); however, a large percentage of the paper survey responses $(51.6 \%, n=32 / 53)$ received in this period were completed by the respondent within the initial fourweek period (Fig. 1).

Most participants responded on the paper survey $(n=$ 408 , 89.5\%). Online responses were more common among: younger respondents (15.4\% among 16-24 years, 
Table 2 Response rate to the Mayi Kuwayu Study preliminary postal distribution $(N=20,000)$, overall and by gender, age group and remoteness

\begin{tabular}{|c|c|c|c|c|c|c|c|c|c|c|c|c|}
\hline & \multicolumn{3}{|l|}{ Major cities } & \multicolumn{3}{|l|}{ Regional } & \multicolumn{3}{|l|}{ Remote } & \multicolumn{3}{|l|}{ Total } \\
\hline & $\bar{n} / \mathrm{N}$ & $\begin{array}{l}\text { response } \\
\text { rate (\%) }\end{array}$ & $95 \% \mathrm{Cl}$ & $\bar{n} / \mathrm{N}$ & $\begin{array}{l}\text { response } \\
\text { rate (\%) }\end{array}$ & $95 \% \mathrm{Cl}$ & $\mathrm{n} / \mathrm{N}$ & $\begin{array}{l}\text { response } \\
\text { rate (\%) }\end{array}$ & $95 \% \mathrm{Cl}$ & $\overline{n / N}$ & $\begin{array}{l}\text { response } \\
\text { rate (\%) }\end{array}$ & $95 \% \mathrm{Cl}$ \\
\hline \multicolumn{13}{|l|}{ Male } \\
\hline $16-24$ & $8 / 821$ & 1.0 & $0.4-1.9$ & $5 / 1178$ & 0.4 & $0.1-1.0$ & $2 / 523$ & 0.4 & $<0.1-1.4$ & $16 / 2522$ & 0.6 & $0.4-1.0$ \\
\hline $25-34$ & $13 / 857$ & 1.5 & $0.8-2.6$ & 9/1101 & 0.8 & $0.4-1.5$ & $3 / 512$ & 0.6 & $0.1-1.7$ & $25 / 2470$ & 1.0 & $0.7-1.5$ \\
\hline $35-49$ & $15 / 708$ & 2.1 & $1.2-3.5$ & $13 / 946$ & 1.4 & $0.7-2.3$ & $1 / 541$ & 0.2 & $<0.1-1.0$ & $31 / 2195$ & 1.4 & $1.0-2.0$ \\
\hline$\geq 50$ & $45 / 756$ & 6.0 & $4.4-7.9$ & $61 / 1017$ & 6.0 & $4.6-7.6$ & $11 / 547$ & 2.0 & $1.0-3.6$ & $117 / 2320$ & 5.0 & $4.2-6.0$ \\
\hline All male & $84 / 3142$ & 2.7 & $2.1-3.3$ & $90 / 4242$ & 2.1 & $1.7-2.6$ & $18 / 2123$ & 0.8 & $0.5-1.3$ & $195 / 9507$ & 2.1 & $1.8-2.4$ \\
\hline \multicolumn{13}{|l|}{ Female } \\
\hline $16-24$ & $23 / 928$ & 2.5 & $1.6-3.7$ & $24 / 1267$ & 1.9 & $1.2-2.8$ & $2 / 553$ & 0.4 & $<0.1-1.3$ & $49 / 2748$ & 1.8 & $1.3-2.4$ \\
\hline $25-34$ & $16 / 964$ & 1.7 & $1.0-2.7$ & $15 / 1148$ & 1.3 & $0.7-2.1$ & $1 / 583$ & 0.2 & $<0.1-1.0$ & $32 / 2695$ & 1.2 & $0.8-1.7$ \\
\hline $35-49$ & $21 / 803$ & 2.6 & $1.6-4.0$ & $16 / 1005$ & 1.6 & $0.9-2.6$ & $2 / 613$ & 0.3 & $<0.1-1.2$ & $39 / 2421$ & 1.6 & $1.1-2.2$ \\
\hline$\geq 50$ & $49 / 886$ & 5.5 & $4.1-7.2$ & $71 / 1148$ & 6.2 & $4.9-7.7$ & $12 / 595$ & 2.0 & $1.0-3.5$ & $132 / 2629$ & 5.0 & $4.2-5.9$ \\
\hline All female & $109 / 3581$ & 3.0 & $2.5-3.7$ & $128 / 4568$ & 2.8 & $2.3-3.3$ & $18 / 2344$ & 0.8 & $0.5-1.2$ & $255 / 10493$ & 2.4 & $2.1-2.7$ \\
\hline TOTAL & $194 / 6723$ & 2.9 & $2.5-3.3$ & $222 / 8810$ & 2.5 & $2.2-2.9$ & $37 / 4467$ & 0.8 & $0.6-1.1$ & $456 / 20000$ & 2.3 & $2.1-2.5$ \\
\hline
\end{tabular}

*18 participants were missing one or more variable of interest (gender, remoteness, age group) or reported "other" to gender. These missing/other data are not presented in the stratified results but are included in the totals

$19.0 \%$ among $25-34$ years, and $17.1 \%$ among $35-49$ years) compared to respondents $\geq 50$ years $(5.2 \%$, $p$-value for fisher's exact test $<0.01$ ); those with higher education levels (16.9\% of university educated) compared to those with lower levels $(5.8 \%$ of those with year 10 or lower education, p-value 0.04); and, respondents whose first language was an Indigenous language (33.3\%) or other $(66.6 \%)$ compared to those whose first language was English $(9.3 \%, p$-value< 0.01$)$. Online responses were also more common in participants who responded after 4 weeks $(20.7 \%)$ compared with those who responded in the first 4 weeks $(9.0 \%)$.

\section{Respondent characteristics to the preliminary postal} distribution

Respondents included 255 females (55.9\%) and 195 males (42.8\%), with 194 respondents from major cities
(42.5\%), 222 respondents from regional areas (48.7\%), and 36 respondents from remote areas (8.1\%) (Table 4). Among age groups, 251 respondents were aged $\geq 50$ (55.0\%), 70 respondents were $35-49$ (15.4\%), 58 respondents were $25-34$ (12.7\%), and 65 respondents were $16-$ 24 (14.3\%). The survey respondents represented a diversity of financial and education levels. Few respondents spoke an Aboriginal and Torres Strait Islander language as their first language $(2.0 \%, n=9)$.

\section{Reasons for non-completion, ineligibility and return to senders}

DHS estimated receiving 500 'returns to sender' (exact number not known), with these surveys destroyed according to a departmental protocol. Sixty-eight calls to the Study helpline were recorded over the period, including from 40 non-Indigenous people who received

Table 3 Response rate to the Mayi Kuwayu Study preliminary postal distribution $(N=20,000)$, by State/Territory

\begin{tabular}{lllll}
\hline State/Territory & Total Responses $(\mathrm{n})$ & Total surveys mailed $(\mathrm{N})$ & Response rate & $95 \% \mathrm{Cl}$ \\
\hline Australian Capital Territory & 10 & 159 & $6.3 \%$ & $3.1-11.3$ \\
New South Wales & 179 & 5415 & $3.3 \%$ & $2.8-3.8$ \\
Northern Territory & 12 & 1904 & $0.6 \%$ & $0.3-1.1$ \\
Queensland & 110 & 6318 & $1.7 \%$ & $1.4-2.1$ \\
South Australia & 25 & 1044 & $2.4 \%$ & $1.6-3.5$ \\
Tasmania & 30 & 598 & $5.0 \%$ & $3.4-7.1$ \\
Victoria & 53 & 1468 & $3.6 \%$ & $2.7-4.7$ \\
Western Australia & 37 & 3094 & $1.2 \%$ & $0.8-1.6$ \\
Total & $\mathbf{4 5 6}$ & $\mathbf{2 0 , 0 0 0}$ & $\mathbf{2 . 3} \%$ & $\mathbf{2 . 1 - 2 . 5}$ \\
\hline
\end{tabular}


Table 4 Characteristics of preliminary Mayi Kuwayu Study postal respondents, overall and by response mode

\begin{tabular}{|c|c|c|c|c|}
\hline & \multirow{2}{*}{$\begin{array}{l}\text { Respondents } \\
\mathrm{N}\end{array}$} & \multicolumn{3}{|l|}{ Response mode } \\
\hline & & \% Paper (n/N) & $\%$ Online $(\mathrm{n} / \mathrm{N})$ & $p$-value \\
\hline TOTAL & 456 & $89.5(408 / 456)$ & $10.5(48 / 456)$ & - \\
\hline \multicolumn{5}{|l|}{ Response received } \\
\hline Within 4 weeks & 390 & $91.0(355 / 390)$ & $9.0(35 / 390)$ & \multirow[t]{2}{*}{0.02} \\
\hline$>4$ to 14 weeks & 66 & $80.3(53 / 66)$ & $19.7(13 / 66)$ & \\
\hline \multicolumn{5}{|l|}{ Gender } \\
\hline Male & 195 & $89.7(175 / 196)$ & $10.3(20 / 196)$ & \multirow[t]{3}{*}{1.0} \\
\hline Female & 255 & $89.4(228 / 255)$ & $10.6(27 / 255)$ & \\
\hline Unclassifiable & 6 & $83.3(5 / 6)$ & $16.7(1 / 6)$ & \\
\hline \multicolumn{5}{|l|}{ Remoteness } \\
\hline Major cities & 194 & $85.6(166 / 194)$ & $14.4(28 / 194)$ & \multirow[t]{4}{*}{0.06} \\
\hline Regional & 222 & $92.8(206 / 222)$ & $7.2(16 / 222)$ & \\
\hline Remote & 37 & $89.2(33 / 37)$ & $10.8(4 / 37)$ & \\
\hline Unclassifiable & 3 & $100(3 / 3)$ & $0(0 / 3)$ & \\
\hline \multicolumn{5}{|l|}{ Age group } \\
\hline $16-24$ & 65 & $84.6(55 / 65)$ & $15.4(10 / 65)$ & \multirow[t]{5}{*}{$<0.01$} \\
\hline $25-34$ & 58 & $81.0(47 / 58)$ & $19.0(11 / 58)$ & \\
\hline $35-49$ & 70 & $82.9(58 / 70)$ & $17.1(12 / 70)$ & \\
\hline$\geq 50$ & 251 & $94.8(238 / 252)$ & $5.2(13 / 252)$ & \\
\hline Unclassifiable & 12 & $83.3(10 / 12)$ & $16.7(2 / 12)$ & \\
\hline \multicolumn{5}{|l|}{ Education } \\
\hline No school & 2 & $100(2 / 2)$ & $0(0 / 2)$ & \multirow[t]{6}{*}{0.04} \\
\hline Up to Year 10 & 189 & $94.2(178 / 189)$ & $5.8(11 / 189)$ & \\
\hline Year 12 & 51 & $94.1(48 / 51)$ & $5.9(3 / 51)$ & \\
\hline Technical or trade & 126 & $87.3(110 / 126)$ & $12.7(16 / 126)$ & \\
\hline University & 77 & $83.1(64 / 77)$ & $16.9(13 / 77)$ & \\
\hline Unclassifiable & 11 & $54.5(6 / 11)$ & $45.5(5 / 11)$ & \\
\hline \multicolumn{5}{|l|}{ Financial status } \\
\hline Some savings & 212 & $89.6(190 / 212)$ & $10.4(22 / 212)$ & \multirow[t]{5}{*}{0.51} \\
\hline Just enough & 144 & $91.0(131 / 144)$ & $9(13 / 144)$ & \\
\hline No savings & 60 & $88.3(53 / 60)$ & $11.7(7 / 60)$ & \\
\hline Unsure & 20 & $100(20 / 20)$ & $0(0 / 20)$ & \\
\hline Unclassified & 20 & $70.0(14 / 20)$ & $30.0(6 / 20)$ & \\
\hline \multicolumn{5}{|l|}{ First language } \\
\hline Indigenous language & 9 & $66.7(6 / 9)$ & $33.3(3 / 9)$ & \multirow[t]{4}{*}{$<0.01$} \\
\hline English & 429 & $90.9(390 / 430)$ & $9.1(39 / 430)$ & \\
\hline Other & 9 & $33.3(3 / 9)$ & $66.7(6 / 9)$ & \\
\hline Unclassifiable & 9 & $100.0(9 / 9)$ & $0(0 / 9)$ & \\
\hline
\end{tabular}

*the category unclassifiable was not included in fisher exact test

the survey and were ineligible to participate. Several Indigenous callers who received the survey in the post were concerned about a perceived link between government and the Study, including concerns about data ownership $(n=12)$. Other callers indicated that they could not complete the survey due to disability and/ or low literacy level $(n=5)$. All invitations for the caller to complete the survey over the phone were declined. One person who received the postal survey was also contacted in the field recruitment over this period and had not completed the survey due to low literacy. 


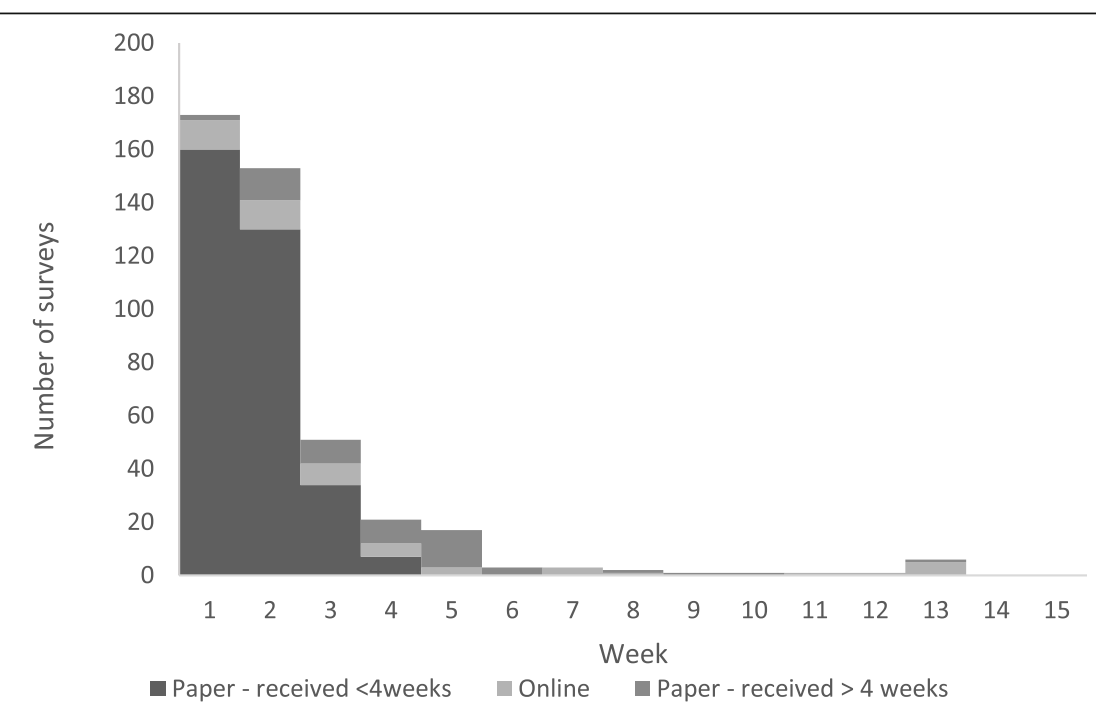

$\mathrm{n}=426$; excludes 30 paper responses missing date of completion.

Fig. 1 Responses to the Mayi Kuwayu preliminary postal distribution by week and response mode. $n=426$; excludes 30 paper responses missing date of completion

\section{Determining the sampling frame for the second stage postal distribution}

The response rates at 4 weeks (Supplementary Table 1) were used to determine the distribution for the next stage of postal distribution (180,000 surveys). There was no material difference in response rates at 4 weeks and 15 weeks in each stratum of the sample (Supplementary Table 2). The sampling approach which had been initially proposed for the Study, prior to consideration of these results, planned to over-sample lower responding groups to achieve 500 responses per strata and maximise sample heterogeneity. However, the results from this preliminary phase demonstrated this was not feasible. For example, males 16-24 years living in major cities had a response rate of $0.6 \%$. This equates to receiving one response per 167 surveys posted; to receive 500 returned surveys, an estimated 83,500 surveys would need to be sent, exceeding the number of Indigenous males enrolled in the Medicare database in this stratum $(n=12,800$ males, major cities, 16-24 years).

The Study team decided that it was a more pragmatic and efficient use of resources to mail the remaining 180, 000 surveys to eligible participants in the high response rate groups (Table 5). Compared to sampling all groups proportionately, over-sampling the high response rate groups increased the expected postal survey returns from $\sim 4000(2.3 \%$ response rate) to $\sim 5500(3.1 \%$ response rate). Updated Aboriginal and Torres Strait Islander Medicare enrolment figures were provided by DHS on 8 February 2019 to determine the strategy for distributing the remaining 180,000 postal surveys (Table 5).

\section{Discussion}

Based on these response rates and a revised postal sampling strategy, we estimated a return of 5900 postal surveys to the Mayi Kuwayu Study, forming the largest Aboriginal and Torres Strait Islander cohort to date. The preliminary postal distribution returned 456 eligible surveys achieving a $2.3 \%$ overall response rate, which is lower than rates in other national surveys for the total Australia population and our estimated response rate of $8-20 \%$ [6]. There was approximately a $6.0 \%$ response rate in the four of the strata levels group (males $\geq 50$ regional, Males $\geq 50$ major cities, Women $\geq 50$ regional, Women $\geq 50$ major cities). The trends are consistent with other Australian cohort studies that have found older age groups and less remote participants are more likely to respond [15]; however, our results contrast with these earlier studies as we did not observe a significant difference in response rate by gender. There was higher uptake of the online survey completion option by younger age groups compared with older age groups, which is also consistent with a recent qualitative study of Indigenous Australians that suggested older participants prefer paper surveys to online [24].

Explanations of non-response are likely to encompass commonly known barriers in Indigenous health research. Indigenous people have described these, including: a history of exploitative research; feeling overresearched; having competing priorities; concerns about government data collection and control; financial barriers; and, not using a participant's first language and associated literacy and numeracy issues [25-27]. There is 
Table 5 Sample for Mayi Kuwayu Study second phase postal distribution and expected number of surveys returned based on preliminary response rate

\begin{tabular}{|c|c|c|c|c|c|c|c|c|c|c|c|c|}
\hline & \multicolumn{3}{|c|}{ Major cities } & \multicolumn{3}{|l|}{ Regional } & \multicolumn{3}{|l|}{ Remote } & \multicolumn{3}{|l|}{ TOTAL } \\
\hline & $\begin{array}{l}\text { Response } \\
\text { rate (\%) }\end{array}$ & $\begin{array}{l}\text { Surveys } \\
\text { sent }(N)\end{array}$ & $\begin{array}{l}\text { Estimated } \\
\text { returns ( } \mathrm{n} \text { ) }\end{array}$ & $\begin{array}{l}\text { Response } \\
\text { rate (\%) }\end{array}$ & $\begin{array}{l}\text { Surveys } \\
\text { sent }(\mathrm{N})\end{array}$ & $\begin{array}{l}\text { Estimated } \\
\text { returns }(n)\end{array}$ & $\begin{array}{l}\text { Response } \\
\text { rate (\%) }\end{array}$ & $\begin{array}{l}\text { Surveys } \\
\text { sent }(N)\end{array}$ & $\begin{array}{l}\text { Estimated } \\
\text { returns }(\mathrm{n})\end{array}$ & $\begin{array}{l}\text { Response } \\
\text { rate (\%) }\end{array}$ & $\begin{array}{l}\text { Surveys } \\
\text { sent }(N)\end{array}$ & $\begin{array}{l}\text { Estimated } \\
\text { returns ( } \mathrm{n})\end{array}$ \\
\hline \multicolumn{13}{|l|}{ Male } \\
\hline $16-24$ & \multicolumn{12}{|c|}{ Not surveyed } \\
\hline $25-34$ & \multicolumn{12}{|c|}{ Not surveyed } \\
\hline $35-49$ & 2.1 & 10,660 & 224 & 1.4 & 12,176 & 170 & & & & 1.7 & 22,836 & 388 \\
\hline$\geq 50$ & 6.0 & 10,351 & 621 & 6.0 & 13,409 & 805 & 2.0 & 5044 & 101 & 5.0 & 28,804 & 1440 \\
\hline \multicolumn{13}{|l|}{ Female } \\
\hline $16-24$ & 2.5 & 13,950 & 349 & 1.9 & 18,020 & 342 & & & & 2.1 & 31,970 & 671 \\
\hline $25-34$ & 1.7 & 15,640 & 266 & 1.3 & 17,605 & 229 & & & & 1.5 & 33,245 & 499 \\
\hline $35-49$ & 2.6 & 12,660 & 329 & 1.6 & 15,293 & 245 & & & & 2.0 & 27,953 & 559 \\
\hline$\geq 50$ & 5.5 & 12,943 & 712 & 6.2 & 16,031 & 994 & 2.0 & 6122 & 122 & 5.0 & 35,096 & 1775 \\
\hline TOTAL & 3.3 & 76,204 & 2515 & 3.1 & 92,534 & 2869 & 2.0 & 11,166 & 223 & 3.1 & 179,904 & 5577 \\
\hline
\end{tabular}

no national data on English literacy for the adult Aboriginal and Torres Strait Islander population; however, literacy rates overall are lower than the total Australian population, particularly for people in remote areas [28] One survey of Aboriginal adults in the Northern Territory (the state where we observed the lowest response rate, $0.6 \%)$ reported that $63 \%(n=554 / 660)$ of participants believed their English literacy skills were inadequate for everyday life [29]. There may be a preference for face-to-face rather than postal survey by some Indigenous participants as this can support: participation of people with low numeracy and literacy; the use of interpreters; and, the use Indigenous researchers to engage participants [6].

The response rate could have been affected by a large quantity of surveys not reaching recipients. We could only rely on the DHS estimate of 'returns to sender' ( $n$ 500). Earlier research has demonstrated counts of 'returns to sender' underestimate the number of surveys not received [14]. Further, in this context high levels of mobility among Indigenous people in some regions may intensify this issue leading to inaccurate addresses in the database [30, 31]. In order to improve estimates, we have commissioned DHS to provide exact 'return to sender' counts at the strata level in the follow-up postal distribution. This will help quantify the proportion of all surveys that did not reach an eligible participant and identify the demographic groups where 'return to sender' is most prevalent and may be particularly hard to reach.

Implications of non-response for recruitment approaches The lower response rates than expected required the Study team to revise the postal sampling strategy to maximise the number of completed surveys and increase efficiency. If the intended minimum baseline of 16,000 respondents is still to be achieved, it will likely require intensification of field recruitment. Depending on response to the next phase, field recruitment numbers may surpass postal recruitment as the primary recruitment method for the baseline cohort.

Prior evidence has demonstrated that low response rates do not necessarily cause non-respondent bias [32-34] and highlighted the importance of collecting as much demographic and population characteristic data as possible. Collection of this type of data enables testing of a specific substantiative analysis and consideration of sample heterogeneity. Mealing et al. found that internal validity in cohort studies is supported by ensuring that there is adequate variation in exposures, a more important factor to consider than response rates [6]. The choice to target specific age groups and regions through the postal survey may have consequences on the heterogeneity of the sample and sub-group analysis, and importantly could reduce the cultural and/or linguistic diversity of the sample.

Field-based recruitment in the Mayi Kuwayu Study will target groups that are under-represented in the postal survey (i.e. younger age groups, remote areas, language groups, prison populations). Focused field-based recruitment can also enhance regional or finer analysis, supporting much needed analysis of community level results and variation in exposures and outcomes between regions [35]. Analysis of the final baseline cohort compared to the total Aboriginal and Torres Strait Islander population is planned.

\section{Improving recruitment approaches}

A number of studies have investigated methods for improving response rates to surveys [3, 32, 36, 37]. One systematic review suggested the response rates can be improved by using: reminder and follow-up letters, 
incentives, television advertising, field recruitment and shorter survey options [37]. Attempts to increase recruitment since the preliminary phase include: television advertising; increased field recruitment; and, increased social media advertising. Other improvements were not possible for the Mayi Kuwayu Study, including: using reminder and follow-up letters (survey materials were sent by DHS and the research team did not have access to addresses); incentivising participation (due to resource and ethical constraints); and, shortening the survey (because this was fixed at the start of the Study). Extensive piloting of the survey substantially reduced the survey length; however, estimates indicate it takes $30 \mathrm{~min}$ to $1 \mathrm{~h}$.

If increased attention is given to field recruitment for the baseline, then some review of these methods could be beneficial in achieving a more heterogeneous sample. The Study has supported different sampling approaches for field recruitment based on community preferences, including convenience; snowballing; strata; and, community-based population; sampling approaches. The dispersed population in regional and remote areas mean that field-based sampling can occur in clusters of communities and regions. These approaches do not necessarily allow for the calculation of response rates and requires more complicated processes to apply population weights and/or adjust for geographic clustering [8]. Where community requests for population level data are made, then application of strata-sampling and cluster sampling approaches (such as the approach used in ABS sampling) may support weighted data for those communities [38]. However, weighting of the total baseline sample may not be possible.

\section{Analysis limitations and strengths}

This is the first analysis of responses rates to a national postal survey of Aboriginal and Torres Strait Islander adults and provides new insights on recruitment approaches for large-scale Indigenous cohort studies. An important strength of this analysis is the value to informing ongoing recruitment approaches in our Study and with Indigenous peoples generally. The initial stage has allowed the opportunity to consider issues of heterogeneity in the sample and non-response bias. Further research in the Mayi Kuwayu Study and other Indigenous cohort studies will continue to assess the cultural appropriateness of different recruitment approaches. Our finding that respondents were more likely to use an online platform when their first language was an Indigenous language compared with respondents who spoke English as a first language is one potential area. It will be important to determine whether these respondents are also living in remote areas given the lower response rates in remote areas where Indigenous language is most likely to be spoken as a first language.
A limitation of our study was the use of postcodes to determine level of remoteness, as $\sim 17.3 \%$ (79/456) of postcodes in this sample crossed boundaries, and may mean that some respondents' remoteness area was incorrectly coded. Geocoding of address data, rather than the use of postcodes, in future analysis would reduce misclassification. Further, this analysis included those who responded, "sent to someone I know" ( $n=26 / 456$ respondents). We considered this a postal response, although these respondents may differ in terms of age, gender and remoteness from the intended recipient (the sample frame). We could not account for these differences in our analysis. This limitation does not influence the overall response rate. It may have minor implications on response rates at the strata level $(6 \%$ of all responses were "sent to someone I know"). In any cases, our response rates could be underestimated, given the known surveys that went to ineligible participants, were returned to sender or did not reach their intended recipient.

\section{Conclusion}

To improve the heterogeneity of Indigenous cohorts, we have determined that a combination of postal and field recruitment approaches remain important methods for recruitment of Aboriginal and Torres Strait Islander adults. In our study, the postal responses rates may have been reduced because of the substantial (19\%) proportion of the total Aboriginal and Torres Strait Islander population living in remote areas (who are more likely to converse in their Indigenous language), concerns relating to the government cover letter, socioeconomic status, levels of English literacy and negative experiences of research. The Study's next recruitment phase was adapted to sample from the highest responding strata by post, increase field recruitment in remote areas and among younger age groups and expand media promotion.

\section{Supplementary information}

Supplementary information accompanies this paper at https://doi.org/10. 1186/s12874-020-00970-8.

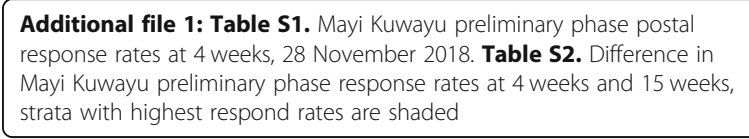

Abbreviations

ABS: Australian Bureau Statistics; DHS: Department of Human Service; $\mathrm{Cl}$ : Confidence interval

\section{Acknowledgements}

The authors acknowledge and thank the participants of Mayi Kuwayu, the National Study of Aboriginal and Torres Strait Islander Wellbeing and acknowledge all the Mayi Kuwayu Study team, community partners, and funding bodies. 


\section{Authors' contributions}

$R L, A W, E B$ and KAT conceived the analysis. FI collated data to Study helpline and AW analysed helpline data. AW and JW conducted the analysis of Mayi Kuwaya data. AW interpreted the results and drafted manuscript. WD reviewed statistical methods and interptetation. All authors (AW, KT, MY, WD $E B, J W, F I, W S, R L)$ provided comments and revisions on the manuscript and approved the final version.

\section{Funding}

The Mayi Kuwayu Study development and preliminary postal distribution was supported by the Lowitja Institute (ref: 1344). The main postal survey distribution was supported by the National Health and Medical Research Council of Australia (ref: 1122273). AW is supported by an Australian Government Research Training Program Scholarship and an ANU Dean's Award Scholarship. RL and EB are supported by the National Health and Medical Research Council of Australia (refs 1088366 and 1136128, respectively). KT is supported by the Lowitja Institute (ref: 1344) and NHMRC (ref: 1122273).

\section{Availability of data and materials}

The Mayi Kuwayu data is governed by a group of Aboriginal and Torres Strait Islander leaders. Request can be submitted to this group for data access.

\section{Ethics approval and consent to participate}

The Mayi Kuwayu Study is approved by the following Human Research Ethics Committee: Australian National University (ANU) HREC (2016/767) Australian Institute of Aboriginal and Torres Strait Island Studies (AIATSIS) (E030/22052015), Central Australian Human Research Ethics Committee (CAHREC) (CA-17-2810), HREC of the Northern Territory Department of Health and Menzies School of Health Research (2017-2804), New South Wales Aboriginal Health \& Medical Research Council (AH\&MRC) HREC (1268/ 17), Western Australian Aboriginal Health Ethics Committee (WAAHEC) (787), The University of Tasmania's HREC (H0016473), The South Australian Aboriginal Health Research Ethics Committee (AHREC) (04-17-723, St Vincent's Hospital Melbourne HREC (132/17), ACT Health HREC (2018/ETH/ 00205) and Metro South HREC (2019/QMS/56115). All respondents are asked to consent to the study prior to answering the survey.

\section{Consent for publication}

Not applicable.

\section{Competing interests}

The authors declare that they have no competing interests.

\section{Author details}

${ }^{1}$ National Centre for Epidemiology and Population Health, Research School of Population Health, Australian National University, Canberra, Australia. ${ }^{2}$ Centre for Aboriginal Economic Policy Research, College of Arts and Social Sciences, Australian National University, Canberra, Australia.

\section{Received: 20 December 2019 Accepted: 5 April 2020}

Published online: 10 June 2020

\section{References}

1. Anderson I, Robson B, Connolly M, Al-Yaman F, Bjertness E, King A, et al. Indigenous and tribal peoples' health (the lancet-Lowitja Institute global collaboration): a population study. Lancet. 2016;388(10040):131-57.

2. Anderson IP, Anderson M, Smylie J. The national Indigenous health performance measurement system. Aust Health Rev. 2008;32(4):626-38.

3. Adamson $L$, Young A, Byles JE. Recruiting for a longitudinal study: who to choose, how to choose and how to enhance participation? In J Mult Res Approach. 2007;1 (2):126-36.

4. Paine SJ, Priston M, Signal TL, Sweeney B, Muller D. Developing new approaches for the recruitment and retention of Indigenous participants in longitudinal research. Mai J. 2013;2(2):121-32.

5. Dyall L, Kepa M, Hayman K, Teh R, Moyes S, Broad JB, et al. Engagement and recruitment of Māori and non-Māori people of advanced age to LiLACS NZ. Aust N Z J Public Health. 2013;37(2):124-31

6. Jones R, Thurber KA, Chapman J, D'Este C, Dunbar T, Wenitong M, et al. Study protocol: our cultures count, the Mayi Kuwayu study, a national longitudinal study of Aboriginal and Torres Strait islander wellbeing. BMJ Open. 2018;8(6):e023861.

7. Sayers SM, Mackerras D, Singh G, Bucens I, Flynn K, Reid A. An Australian Aboriginal birth cohort: a unique resource for a life course study of an Indigenous population. A study protocol. BMC Int Health Hum Rights. 2003; 3(1):1.

8. Hewitt B. The longitudinal study of indigenous children: implications of the study design for anlaysis and results. Brisbane: Institute for Social Science Research, University of Queensland, Report prepared for Department of Families H, Community Services and Indigenous Affairs; 2012.

9. The SEARCH Investigators. The study of environment on aboriginal resilience and child health (SEARCH): study protocol. BMC Public Health. 2010;10(287):1-8.

10. Thomas DP, Briggs VL, Couzos S, Davey ME, Hunt JM, Panaretto KS, et al. Research methods of talking about the smokes: an international tobacco control policy evaluation project study with Aboriginal and Torres Strait islander Australians. Med J Aust. 2015;202(S10):S5-S12.

11. Gubhaju L. In: Health REiACaA, editor. 'Next Generation': Youth Wellbeing Study. Melbourne: University of Melbourne; 2017.

12. Australian Bureau of Statistics. 3238.0.55.001 - Estimates of Aboriginal and Torres Strait Islander Australians, June 2016. Canberra: Australian Government; 2018

13. Gubhaju L, McNamara BJ, Banks E, Joshy G, Raphael B, Williamson A, et al. The overall health and risk factor profile of Australian aboriginal and Torres Strait islander participants from the 45 and up study. BMC Public Health. 2013;13(1):661

14. Lee C, Dobson AJ, Brown WJ, Bryson L, Byles J, Warner-Smith P, et al. Cohort profile: the Australian longitudinal study on women's health. Int J Epidemiol. 2005;34(5):987-91

15. Brown WJ, Bryson L, Byles JE, Dobson AJ, Lee C, Mishra G, et al. Women's health Australia: recruitment for a National Longitudinal Cohort Study. Women \& Health. 1999;28(1):23-40.

16. Banks E, Redman S, Jorm L, Armstrong B, Bauman A, Beard J, et al. Cohort profile: the 45 and up study. Int J Epidemiol. 2008:37(5):941-7.

17. Thompson SC, Woods JA, Katzenellenbogen JM. The quality of Indigenous identification in administrative health data in Australia: insights from studies using data linkage. BMC Med Inform Decis Mak. 2012;12(1):133.

18. Australian Institute for Health and Welfare. Towards better Indigenous health data. Cat no. IHW 93. Australian Institute for Health and Welfare editor. Canberra: AlHW; 2013

19. Australian Institute for Health and Welfare. In: Welfare AlfHa, editor. Improving Indigenous identification in mortality estimates. Canberra: AlHW; 2019.

20. Draper GK, Somerford PJ, Pilkington AAG, Thompson SC. What is the impact of missing Indigenous status on mortality estimates? An assessment using record linkage in Western Australia. Aust N Z J Public Health. 2009;33(4): $325-31$

21. Medicare Australia. Aboriginal and Torres Strait Islander Medicare enrolment and amendment form Canberra. 2019 Available from: https://www. humanservices.gov.au/sites/default/files/2018/10/ms018-1807en.pdf.

22. Australian Bureau of Statistics. 1270.0.55.005 Australian Statistical Geography Standard (ASGS): Volume 5 - Remoteness Structure Canberra: Australian Bureau of Statistics; 2016.

23. Australian Bureau of Statistics. 1270.0.55.006 - Australian Statistical Geography Standard (ASGS): Correspondences, July 2011. Canberra: Australia Bureau of Stasitics; 2011.

24. Green M, Anderson K, Griffiths K, Garvey G, Cunningham J. Understanding indigenous Australians' experiences of cancer care: stakeholders' views on what to measure and how to measure it. BMC Health Serv Res. 2018;18(1):982.

25. Laycock A, Walker D, Harrison N, Brands J. Researching indigenous health: a practical quide for researchers. Melbourne: Lowitja Institute; 2011.

26. Martin K Mirraboopa B. Ways of knowing, being and doing: a theoretica framework and methods for indigenous and indigenist re-search. J Aust Stud. 2003;27(76):203-14.

27. Moreton-Robinson A. Towards a new research agenda? Foucault, whiteness and indigenous sovereignty. J Sociol. 2006;42(4):383-95.

28. Ratcliffe R, Boughton B. The relationship between low adult literacy levels and Aboriginal family and community engagement in educational decision making. Aust Int J Rural Educ. 2019:29(1):1.

29. Stewart A, Shalley F. A statistical overview: aboriginal adult LLN in the Northern Territory. Darwin: Office of the Pro Vice Chancellor - Indigenous Leadership, Charles Darwin University; 2017. 
30. Foster D, Mitchell J, Ulrik J, Williams R. Population and mobility in the town camps of Alice Springs. Alice Springs: Desert Knowledge Cooperative Research Centre; 2005

31. Warchivker I, Tjapangati T, Wakerman J. The turmoil of Aboriginal enumeration: mobility and service population analysis in a central Australian community. Aust N Z J Public Health. 2000;24(4):444-9.

32. Asch DA, Jedrziewski MK, Christakis NA. Response rates to mail surveys published in medical journals. J Clin Epidemiol. 1997;50(10):1129-36.

33. Rindfuss RR, Choe MK, Tsuya NO, Bumpass LL, Tamaki E. Do low survey response rates bias results? Evidence from Japan. Demogr Res. 2015;32:797828.

34. Bootsma-van der Wiel AV, Van Exel E, De Craen AJ, Gussekloo J, Lagaay AM, Knook DL, et al. A high response is not essential to prevent selection bias: results from the Leiden 85-plus study. J Clin Epidemiol. 2002:55(11):1119-25.

35. Wright A, Lovett R, Roe Y, Richardson A. Enhancing national data to align with policy objectives: Aboriginal and Torres Strait islander smoking prevalence at finer geographic levels. Aust Health Rev. 2018;42(3):348-55.

36. Edwards P, Roberts I, Clarke M, DiGuiseppi C, Pratap S, Wentz R, et al. Increasing response rates to postal questionnaires: systematic review. BMJ. 2002;324(7347):1183.

37. Howell SC, Quine S, Talley NC. Ethics review and use of reminder letters in postal surveys: are current practices compromising an evidence-based approach? Med J Aust. 2003;178(1):43.

38. Dey EL. Working with low survey response rates: the efficacy of weighting adjustments. Res High Educ. 1997;38(2):215-27.

\section{Publisher's Note}

springer Nature remains neutral with regard to jurisdictional claims in published maps and institutional affiliations.

Ready to submit your research? Choose BMC and benefit from:

- fast, convenient online submission

- thorough peer review by experienced researchers in your field

- rapid publication on acceptance

- support for research data, including large and complex data types

- gold Open Access which fosters wider collaboration and increased citations

- maximum visibility for your research: over 100M website views per yea

At BMC, research is always in progress.

Learn more biomedcentral com/submissions 